\title{
A TOTAL RISK ASSESSMENT IN AN ENTERPRISE
}

\author{
Wiesław WASILEWSKI \\ Faculty of Economics and Management \\ University of Zielona Góra, Poland \\ e-mail: w.wasilewski@wez.uz.zgora.pl
}

\begin{abstract}
Risk assessment is an important task of risk management. It must take various aspects into consideration. For this reason the risk management involves various scientific disciplines: mathematics, psychology, law etc. Every institution must deal with many different kinds of risk. The question is: in order to ensure the continuation of the company, is it important to assess individual risk or to identify and evaluate the entire overall risk to the enterprise. This article aims to present a method of calculating the total organizational risk in relation to the ROI-return on investment (justifying the critical importance of profit [loss] in ensuring the continued operation of the entity).
\end{abstract}

Key words: risk, risk management, risk assessment, ERM, total risk, business continuity management.

\section{Introduction}

One of the crucial tasks of risk management is the assessment of identified risk. It should take various aspects into consideration. The quantitative, legal and psychological points of view are of practical importance in this case.

Thus, on the one hand, the quantitative risk measures should be analyzed critically, extensively described in theory and applied in practice. On the other hand, the issues arising due to accepting a risk must also be addressed. The answer to these issues implies the need for taking psychological factors into consideration.

"Risk analysis is a technical and systematic process to examine identified risks, isolate causes, determine the relationship to other risks, and express the impact in terms of probability and consequence of occurrence. Analysis begins with a detailed study of the risk issues that have been identified. The objective is to gather enough information about the risk issues to judge the probability of occurrence and cost, schedule, and technical consequences if the risk occurs" [7, p. 765].

Every institution must deal with many different kinds of risks. The question is: whether, to ensure the continuation of the company, it is important to assess individual risks, or to identify and evaluate the entire overall risk to the enterprise.

This article aims to present a method of calculating the total risk to organizations in relation to the planned return (justifying the critical importance of profit [loss] in ensuring the continued operation of the entity).

\section{$2 \quad$ Risk and its assessment}

For a start, we should ban the term measurement and say risk 'assessment'. Risks are about the future, an appreciation of potential difficulties or disasters. Measurements can only be about things that exist now or were recorded in the past. To jump to the future we need to make assumptions and to use models that are logical constructs build on these assumptions. Assumptions and models can never be validated in an absolute sense but they may be deemed acceptable in certain limited circumstances in order to support certain decisions.

Decisions that depend on risk descriptions are many. For example, on a short time scale, assuming markets behave normally, risk assessments should help make efficient use of resources, that is, achieve the most desirable risk/return trade-offs. Over the long term, managers as well as regulators are concerned about the viability of financial institutions. But a firm's survival depends not only on capital now but also on a host of other factors such as a good reputation, a viable franchise, an astute and cautious management, and a well-developed risk management function [9, p. 2].

Care should also be taken to capture information about the inherent risk. If this is not done the organisation will not know what its exposure will be if control should fail. Knowledge about the inherent risk also allows better consideration of whether there is overcontrol in place - if the inherent risk is within the risk appetite, resources may not need to be expended on controlling that risk. 
This need to have knowledge about both inherent and residual risk means that the assessment of risk is a stage in the risk management process which cannot be separated from addressing risk; the extent to which the risk needs to be addressed is informed by the inherent risk whereas the adequacy of the means chosen to address the risk can only be considered when the residual risk has been assessed [18, p. 20].

Risk assessment assumes that the notion of risk is defined in a precise and measurable way. The concept of risk is understood as "the possibility of nonachievement of an explicitly formulated or implicitly arising objective of an enterprise" (cf. [2]). The possibility of non-achievement of a given objective results from uncertainty. It constitutes and is the very cause of risk. The definition clearly implies that an objective is always the point of reference to risk [16, p.12]. The objective describes the future condition that the enterprise is trying to achieve. Usually, the condition may be presented with the use of specific measuring values (indexes) such as e.g. profit, cost, turnover, the use of production capacities, market share. The objectives are often described in such a manner that at least (in the case of indexes where the highest possible value is striven for) or at the most the particular value should be achieved (in the case of indexes where the lowest possible value is desirable).

The non-achievement of objective means that the value is lower or alternatively that it has been exceeded. Such objectives are called level targets.

It occurs rarely that the value described by objective should be achieved precisely (point target).

Implementation of risk management in the enterprise has primarily two objectives:

- risk awareness among employees of the enterprise is increased,

- the appropriate methods are used to handle the specific risk.

Risk management deals with the pure and speculative risk. At the pure risk only pure loss is possible (material damages, financial losses, threats to life, ...). At the speculative risk besides the possibility of losses there is also a possibility of profit.

A simplified classification of risk is presented by P. Drucker, who identifies four types of risk. The first is a risk that a person must accept, such as driving a car to travel, or the use of tools that allow you to perform an action. The second type is a risk which a person can take and allow, which is taken, for instance, while skiing or doing a sport. The third is the opposite and is a risk that we cannot allow. It is incurred when success of a decision depends on luck, and the consequences can be tragic and irreversible, such as overtaking a car just before a hill. And finally, the fourth type - risks that we must take such as a desperate jump from a building on fire (cf. [11, pp. 1314]). This interpretation made by the famous guru of modern management methods makes it entirely clear that risk is an essential element of life and it can be found in almost every area of human activity.

Making choices in situations of risk comes down to two important things: how attractive the consequences of the action are and how big the chances that we will reach the desired results are. This regularity was already noticed by Pascal, who pointed out that when taking a risk not only the consequences should be taken into account, but also the probability of their occurrence. He refers to natural phenomena, noting that many people feel excessive anxiety when they hear thunder lightning, although the incidence of death due to lightning is small (cf. [13, pp. 43-47]). Pascal comments on that with the following remark: „Fear of danger should be proportionate not only to the seriousness of danger, but also the probability with which this event can occur" (cf. [4, p. 58]).

While analyzing the risk of a project we can use two methods of quantification - formal and descriptive. Using a formalized method, the measured risk is quantitative. This approach includes the size and level of probability of risk occurrence, as well as a range of possible outcomes (in most cases it is a normal distribution), the expected timing of their occurrence and the expected frequency of risky events arising from a particular source, area or type of risk.

In the descriptive method, the measured risk is of a qualitative character, and the probability in this approach is described as high, medium or low. This approach, however, has a limited application, since such descriptions of probabilities are imprecise and ambiguous, and therefore they can be understood and interpreted differently by different people. Thus, in order to determine the level of probability accurately, we should use both, the qualitative and quantitative approaches (cf. [10, p. 46]). 
Both in the literature and in practice it is universally agreed that in the case of quantitative risk assessment both the scale of possible losses and the probability of their occurrence should be taken into consideration ${ }^{1}$. This assessment needs to be done by evaluating both the likelihood of the risk being realized, and of the impact if the risk is realized. [18, p. 19]. Tyszka and Zaleśkiewicz claim, e.g., that the combination of the possible loss volume and its probability constitute a natural risk measure [12, p. 59].

In order to implement this method of assessment, the following questions must be answered:

- how to determine the size and probability of a loss?

- how to "combine" the size and probability of a loss in a reasonable way?

It is difficult to answer the first question, since there is often a lack of statistical data, which leads to the necessity of employing a subjective assessment. Such an assessment is influenced by cognitive factors. Jonen, Lingnau and Sagawe therefore suggested using the Analytic Hierarchy Process (AHP) as an instrument that could reduce negative effects of these factors and increase the transparency of assessment results [6].

The use of a risk matrix is described broadly in the literature on the subject as an adequate instrument allowing estimation of the size of risk (magnitude of losses, and their probabilities) using the quality parameters in the absence of sufficient quantitative data. Another advantage of this tool is that it can take into account the psychological characteristics of an individual decision maker, who estimates the likelihood and extent of losses. The information is filtered through the subjective ,risk appetite”.

Variance (alternatively a standard deviation) constitutes the qualitative risk measure which is most frequently applied both in theory and in practice.

Variance is regarded as an improper risk measure for two reasons

- variance does not measure deviations from a particular goal value, but from the anticipated value; as a rule, these two values are not identical,

- according to the variance formula, both the nonachievement and exceeding the goal value are regarded as a loss; this, however, only concerns the point targets.

\footnotetext{
${ }^{1}$ In single cases it is recommended to consider only the probability of loss as a risk measure (cf. e.g [14, p. 131]).
}

The second point of criticism may be omitted in the case of level target, since a negative or alternatively positive semivariance can be used instead of the variance (cf. e.g. [14, p. 130]).

If in the semivariance formula the expected value is replaced with a given value of goal (a generalized semivariance) then the first point of criticism may be skipped as well.

As far as level targets are concerned, the generalized semivariance does not provide any satisfactory information on the risk volume. Namely, it only takes negative deviations from a given goal value (i.e. the loss) into account, not the positive deviations (i.e. profits), however. Zaleśkiewicz [15, p. 90] claims that 'according to the rules of decisive analysis, when assessing the risk volume, four parameters should be taken into consideration: (1) loss volume, (2) loss probability, (3) profit amount and (4) profit probability'. The comprehension of positive deviations is also of great significance from the point of view of legal assessment of risk. The legally acceptable risk should be distinguished from unlawful danger. Therefore, the relations between risk, costs and benefits need to be analyzed very carefully (cf. [16, p. 16]).

This is the reason why the risk rate is considered to be the most effective risk measure in the case of level targets. The risk rate is a quotient of average negative deviations from goal values and average positive deviations (cf. [2, p. 69]; [16, p. 52]). The lower the rate, the lower the risk.

\section{Risk aggregation}

Risk aggregation is a process to identify and illustrate the interaction of several, differently correlated individual risks of an organization in order to obtain the overall risk [17, p. 7].

Broadly, risk aggregation refers to efforts by firms to develop quantitative risk measures that incorporate multiple types or sources of risk. The most common approach is to estimate the amount of "economic capital" that a firm believes is necessary to absorb potential losses associated with each of the included risks. This is typically accomplished via mathematical or statistical techniques designed to assess the likelihood of potential adverse outcomes, although the use of specific stress scenarios is also relatively common [3, p. 1]. 
S.R. David ([5], p. 3) identifies the following six situations where some type of Risk Aggregation may be appropriate:

- Type 1: Aggregating Risks for a "Single Risk" where multiple outcomes are possible (e.g. fire consequence can range from no harm to multiple fatalities, with each outcome having a different likelihood),

- Type 2: Aggregating Risks to an individual or group of people from a range of possible Accidents or Activities or Systems,

- Type 3: Aggregating Risks for all the possible Accidents that a System might cause,

- Type 4: Aggregating Risks for all the Systems / Facilities / Operations within an organisation,

- Type 5: Aggregating Risks for multiple Systems functioning together (e.g. "System of Systems"),

- Type 6: Aggregating Risks for multiple Systems that may not be independent (e.g. due to "Domino Effects" or "Common Causes").

Typically Risks are assessed from the bottom up starting at the most elemental level (e.g., instrument by instrument) and by risk type (i.e., separately for credit, market and other risks). Risk aggregation rules are primitive: often down to a simple addition of standard deviations, sometimes, a square root of the sum of the squares if there is no evidence of dependency $[9$, p. 4].

Some firms remain sceptical of the value of these methods and techniques, particularly efforts to reduce all risks into a single number. Others believe that there is a need for a common metric that allows risk-return comparisons to be made systematically across business activities whose mix of risks may be quite different (e.g., insurance vs. trading). However, even among those firms that are at the forefront of exploring economic capital approaches, there is wide variation in the manner in which aggregated risk measures such as economic capital are used for risk management decision-making [3, p. 1].

\section{$4 \quad$ Total Risk}

Risk is the result of the cumulative total of all the risks faced by an organization. The estimation of this, however, is difficult because in order to obtain a numeric value, creating a simple sum of the individual risks of its components is not sufficient. The total risk of an entity is a complex relationship of individual risks. It takes into account all possible events which may give rise to risk, hence its estimation is of great importance for the organization, especially when analyzing the situation. The organization conducts a systematic risk management process, which seeks to ensure the continuation of its activities by analyzing different events (and thus risk). The total risk takes into account the possibility of a variety of different events factored simultaneously in different configurations.

Every entrepreneur who is familiar with the profit and loss statement (one of the three basic financial statements) may on his own try to identify the financial and operational risks in his company. The subsequent sections provide an account of potential sources of operational and financial risks.

„Despite the trendy catchphrase, Total Risk Management has deep intellectual roots in economics, statistics, and mathematics and is based on research that can be traced back to the very foundations of probability theory (Ramsey, 1926), statistical inference (Savage, 1954), and game theory (von Neumann and Morganstern, 1944)" [8, p. 3]. Total risk can be estimated on the basis of definitive analysis of the relationship between the value of sales, operating profit and net profit. Its scale shows us the extent to which the company's net profit will increase due to increased sales values, taking into account financial income and expenditure.

\section{$5 \quad$ Assessment of Total Risk}

This article aims to present a useful method of risk assessment, Risk which is generated by numerous events occurring simultaneously. Each event will be illustrated in a document which forms part of the financial statements - the profit and loss account (P\&L).

Sample document with comparative variants is shown in Table 1. The natural goal of any company (including non-profit) is to stay on the market, the condition being to obtain a profit in the final outcome (although this alone is not a sufficient condition). Many situations can affect the value of each item of the statement, and thus lead to the destruction of any chance for profit, or a notable loss.

The formalization of this situation is as follows:

- objective: to achieve a given value of profit,

- risk: the possibility of achieving a profit other than the given value.

Event: a situation whose existence has an effect on the objective (its failure). 
Table 1. Separate income statement (source: self study)

\begin{tabular}{|c|c|c|c|}
\hline \multirow[b]{2}{*}{ No. } & \multirow[b]{2}{*}{ Item } & \multicolumn{2}{|c|}{ Sum (zł) } \\
\hline & & This Year & $\begin{array}{c}\text { Previous } \\
\text { Year }\end{array}$ \\
\hline 1 & 2 & 3 & 4 \\
\hline A & Net revenues from sales & & \\
\hline $\mathrm{B}$ & Operating expenses & & \\
\hline $\mathrm{C}$ & Profit (loss) on sales (A-B) & & \\
\hline $\mathrm{D}$ & Other operating revenues & & \\
\hline E & Other operating expenses & & \\
\hline $\mathrm{F}$ & Profit (loss) on operating activities (C+D-E) & & \\
\hline G & Financial revenues & & \\
\hline $\mathrm{H}$ & Financial expenses & & \\
\hline I & Profit (loss) on business activities (F+G-H) & & \\
\hline $\mathrm{J}$ & Result on extraordinary events & & \\
\hline $\mathrm{K}$ & Gross profit (loss) $(\mathrm{I}+\mathrm{J})$ & & \\
\hline $\mathrm{L}$ & Income tax ( CIT - 19\%) & & \\
\hline M & Other statutory reductions in profit (increases in loss) & & \\
\hline $\mathrm{N}$ & Net profit (loss) (K-L-M) & & \\
\hline
\end{tabular}

Examples of events affecting individual Profit and Loss Account entries are illustrated in Table 2.

Table 2. Examples of events affecting the profit and loss account (source: self study)

\begin{tabular}{|c|c|c|}
\hline No. & Item & Event affecting objective \\
\hline 1 & 2 & 3 \\
\hline A & net revenues from sales & $\begin{array}{l}\text { - competition entering the market } \\
\text { - weather conditions }\end{array}$ \\
\hline $\mathrm{B}$ & operating expenses & $\begin{array}{l}\text { - increase in costs associated with } \\
\text { the consumption of materials and energy } \\
\text { - the increase in taxes } \\
\text { - salary increases }\end{array}$ \\
\hline $\mathrm{C}$ & profit (loss) on sales (A-B) & - \\
\hline $\mathrm{D}$ & other operating revenues & - with holding of grants \\
\hline $\mathrm{E}$ & other operating expenses & $\begin{array}{l}\text { - loss on disposal of non-financial assets greater than } \\
\text { planned }\end{array}$ \\
\hline $\mathrm{F}$ & $\begin{array}{l}\text { profit (loss) on operating activi- } \\
\text { ties }(\mathrm{C}+\mathrm{D}-\mathrm{E})\end{array}$ & - \\
\hline G & financial revenues & $\begin{array}{l}\text { - unpaid interest } \\
\text { - non-payment of dividends, share profits } \\
\text { - profit on disposal of investments less than planned }\end{array}$ \\
\hline $\mathrm{H}$ & financial expenses & $\begin{array}{l}\text { - interest } \\
\text { - loss on disposal of investments }\end{array}$ \\
\hline $\mathrm{I}$ & $\begin{array}{l}\text { profit (loss) on business activities } \\
(\mathrm{F}+\mathrm{G}-\mathrm{H})\end{array}$ & ( \\
\hline $\mathrm{J}$ & result on extraordinary events & - extraordinary losses \\
\hline $\mathrm{K}$ & gross profit (loss) $(\mathrm{I}+\mathrm{J})$ & - \\
\hline $\mathrm{L}$ & income tax ( CIT - 19\%) & - increase in Tax rate \\
\hline M & $\begin{array}{l}\text { other statutory reductions in profit } \\
\text { (increases in loss) }\end{array}$ & - \\
\hline $\mathrm{N}$ & net profit (loss) (K-L-M) & - \\
\hline
\end{tabular}


Table 3. Example separate income statement (source: self study)

\begin{tabular}{|c|c|c|c|}
\hline \multirow{2}{*}{ No. } & \multirow{2}{*}{ Item } & \multicolumn{2}{|c|}{ Sum (zł) } \\
\hline & & This Year & Prior Year \\
\hline 1 & 2 & 3 & 4 \\
\hline $\mathrm{A}$ & Net revenues from sales & 68593 & 100000 \\
\hline $\mathrm{B}$ & Operating expenses & 68949 & 60000 \\
\hline $\mathrm{C}$ & Profit (loss) on sales (A-B) & -356 & 40000 \\
\hline $\mathrm{D}$ & Other operating revenues & 1093 & 1000 \\
\hline $\mathrm{E}$ & Other operating expenses & 594 & 600 \\
\hline $\mathrm{F}$ & Profit (loss) on operating activities (C+D-E) & 143 & 40400 \\
\hline $\mathrm{G}$ & Financial revenues & 395581 & 30000 \\
\hline $\mathrm{H}$ & Financial expenses & 6019 & 6000 \\
\hline $\mathrm{I}$ & Profit (loss) on business activities (F+G-H) & 389705 & 64400 \\
\hline $\mathrm{J}$ & Result on extraordinary events & 0 & 0 \\
\hline $\mathrm{K}$ & Gross profit (loss) $(\mathrm{I}+\mathrm{J})$ & 389705 & 64400 \\
\hline $\mathrm{L}$ & Income tax ( CIT - 19\%) & 74044 & 12236 \\
\hline M & $\begin{array}{l}\text { Other statutory reductions in profit (increases in } \\
\text { loss) }\end{array}$ & 0 & 0 \\
\hline $\mathrm{N}$ & Net profit (loss) (K-L-M) & 315661 & 52164 \\
\hline
\end{tabular}

To assess the risk of failure to achieve the given the value of profit, as a result of events affecting the individual items of the profit and loss account, a suitable model should be created which includes the probability of not achieving the objective.

The general model is as follows:

- $\quad$ Profit $=(A-B)+(D-E)+(G-H)+J-L-M$

where Profit is the amount obtained by calculations made on the values of the Profit and Loss Account, after taking into account the impact of unforeseen events on its individual components,

- $\quad \mathrm{P}=\mathrm{P}($ Profit $<$ Planned_Profit $)$

where Planned_Profit is the final value of P\&L planned by the company for the current financial year.

\section{Case study}

\subsection{Case study - assumptions}

Enterprise $\mathrm{X}$ established Profit and Loss Account as follows (see Table 3). Rows A, B, D, E, G and $\mathrm{H}$ in the example above are elements of the profit and loss account which may change due to unforeseen events.

Each of them has been assigned a variable symbol:

p1 - net revenues from sales,

k1 - operating expenses,

$\mathrm{p} 2$ - other operating revenues,

$\mathrm{k} 2$ - other operating expenses,

p3 - financial revenues,

$\mathrm{k} 3$ - financial expenses.
The next element of the research conducted takes into account a possible deviation of $20 \%$ assumed by the company profit and loss statements for three different distributions of random variables.

Three different scenarios will therefore be explored:

- deviation from the plan of each listed component of the profit and loss of $\pm 20 \%$, adopting a normal distribution,

- deviation from the plan of each listed component of the profit and loss of $\pm 20 \%$, adopting uniform distribution,

- deviation from the plan of each listed component of the profit and loss of $\pm 20 \%$, adopting a triangular distribution.

All calculations will be carried out in the program 'Rproject', which is used for mathematical and statistical calculations. It has many built-in features for the quick solution of difficult and complex equations. The following will be used primarily:

- the possibility to use the program as a calculator,

- a random number generator with any distribution,

- rdistributionname ( $\mathrm{m}$, distribution parameters), where $\mathrm{m}$ is a natural number and indicates the amount of random numbers:

- for normal distribution we have: $\operatorname{rnorm}(\mathrm{m}, \mu, \sigma)$

where: $\mu$ - mean value for a given interval, and $\sigma$ - standard deviation, 
Table 4. First scenario assumptions (source: self study)

\begin{tabular}{|c|l|c|c|}
\hline No. & \multicolumn{1}{|c|}{ Item } & Plan & Possible realization \\
\hline A & Net revenues from sales & 100000 & {$[80000 ; 120000]$} \\
\hline B & Operating expenses & 60000 & {$[48000 ; 72000]$} \\
\hline D & Other operating revenues & 1000 & {$[800 ; 1200]$} \\
\hline E & Other operating expenses & 600 & {$[480 ; 720]$} \\
\hline G & Financial revenues & 30000 & {$[24000 ; 36000]$} \\
\hline H & Financial expenses & 6000 & {$[4800 ; 7200]$} \\
\hline N & Net profit (loss) & 52164 & \\
\hline
\end{tabular}

- for uniform distribution we have:

runif(m, a, b)

where: $a$ - the beginning of the interval, $b$ - end of range,

- for triangular distribution we have:

rtriangle(m, a, b, c)

where: $\mathrm{a}$ - the beginning of the interval, $\mathrm{b}$ - end of the interval, and c - middle of range.

- commands counting:

- mean value mean(w),

- standard deviation sqrt(var(w)),

- minimum value $\min (\mathrm{w})$,

- highest value $\max (\mathrm{w})$

where $\mathrm{w}$ is vector of numbers,

- command that allows to calculate the Probability of failure to obtain the planned profit for the company:

pdistributionname(Planned_Profit, distribution parameters)

- for normal distribution we have:

pnorm(Planned_Profit, $\mu, \sigma)$

where: $\mu$ - mean value for a given interval,

and $\sigma$ - standard deviation,

- for uniform distribution we have:

punif(Planned_Profit, a, b)

where: a - the beginning of the interval,

$\mathrm{b}$ - end of range,

- for triangular distribution we have:

ptriangle(Planned_Profit, a, b, c)

where: a - the beginning of the interval,

$\mathrm{b}$ - end of the interval, and c - middle of range.

Since the company cannot be certain of the individual elements of profit and loss, it can only estimate them, which allows the possibility of changing them, the value of these components will be selected by random selection. In order to validate the calculations performed for each component of the profit and loss account a random 100-element test will be drawn. It should be kept in mind that the sample given in the following case is chosen at random and each subsequent draw will select other values.

According to company plan:

$$
\text { Profit }=(A-B)+(D-E)+(G-H)+J-L-M
$$

However if possible causes of changes in the plan are accepted and these changes were randomly selected, then the gross profit is as per formula:

$$
\text { GrossProfit }=(\mathrm{p} 1-\mathrm{k} 1)+(\mathrm{p} 2-\mathrm{k} 2)+(\mathrm{p} 3-\mathrm{k} 3)+\mathrm{J}
$$

Corporate income tax is:

$$
\text { CIT }=\text { GrossProfit } * 0,19
$$

Finally, net profit is expressed by the formula:

Profit $=$ GrossProfit - CIT .

In Figures 1, 2 and 3 'Profit' is labeled as 'Zysk'.

\subsection{Case study - calculation}

\subsubsection{Scenario 1}

Scenario assumptions:

- variation specified in the profit and loss statement differs from the plan values by $\pm 20 \%$,

- all listed components are random variables normally distributed with parameters $\mu$ and $\sigma$, where:

- $\mu$ is the mean value to be adopted by variation of the given interval,

- the value of $\sigma$ (standard deviation) will be determined by applying the rule of "three sigma", which says that for a normal distribution $99,7 \%$ of the features is only $\leq 3 \sigma$, which is within the ranges established in Table 4. 


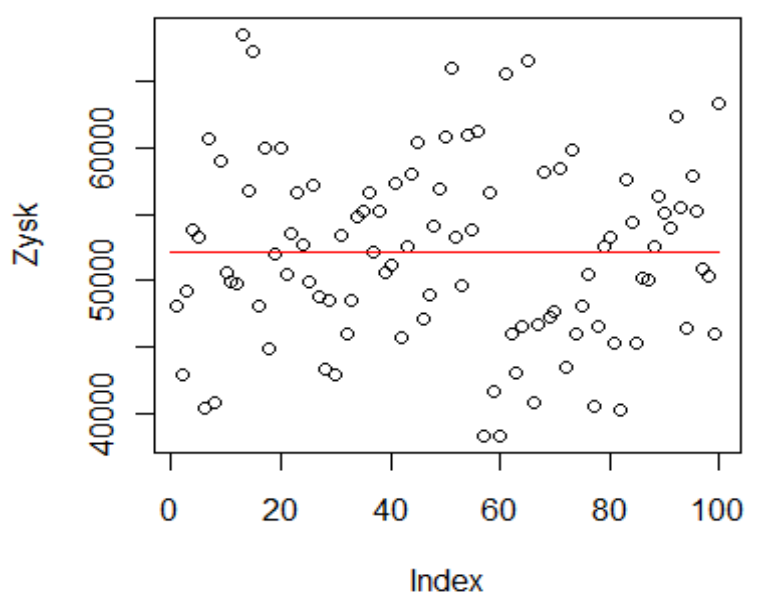

Figure 1. Profit values obtained in scenario 1 (source: self study)

We have:

- net revenues from sales are random variable $\mathrm{p} 1$ with parameters $\mu=100000$ and $\sigma=6667$ (p1 N(100000,666 $\left.7^{2}\right)$,

- operating expenses are random variable $\mathrm{k} 1$ with parameters $\mu=60000$ and $\sigma=4000$ $\left(\mathrm{k} 1 \sim \mathrm{N}\left(60000,4000^{2}\right)\right)$,

- other operating revenues are random variable $\mathrm{p} 2$ with parameters $\mu=1000$ and $\sigma=67$ $\left(\mathrm{p} 2 \sim \mathrm{N}\left(1000,67^{2}\right)\right)$,

- other operating expenses are random variable $\mathrm{k} 2$ with parameters $\mu=600$ and $\sigma=40$ $\left(\mathrm{k} 2 \sim \mathrm{N}\left(600,40^{2}\right)\right)$,

- financial revenues are random variable p3 with parameters $\mu=30000$ and $\sigma=2000$ (p3 N $\left(30000,2000^{2}\right)$ ),

- financial expenses are random variable $\mathrm{k} 3$ with parameters $\mu=6000$ and $\sigma=400$ $\left(\mathrm{k} 3 \sim \mathrm{N}\left(6000,400^{2}\right)\right)$.

A value is drawn for each of the above, assuming normal distribution, and the result is stored as a variable. The pattern is replicated for the rest of the calculations, leading to a net profit shown in Fig. 1.

Basic measures of location and dispersion for Profit:

- highest profit that the firm may achieve in accordance with the assumptions of scenario 1 :

$>\max ($ Profit)

[1] 68483,24

- minimum profit:

$>\min ($ Profit)

[1] 38366,13

- average profit with randomly selected parameters:

$>$ mean(Profit)

[1] 52027,75
- standard variation:

$>$ sd(Profit)

[1] 6784,96

Verification if the Profit function is normally distributed at significance level $\alpha=0,05$ :

- lillie.test(Profit)

Lilliefors (Kolmogorov-Smirnov) normality test da-

ta: Profit

$\mathrm{D}=0,0523, \mathrm{p}$-value $=0,7185$

Coefficient $p$-value $=0,7185>\alpha=0,05$, therefore it can be agreed that the sample is normally distributed.

The size of the probability that the financial result achieved will be less than planned:

- $\operatorname{pnorm}(52164$, mean(Profit), sd(Profit))

[1] 0,5080105

Thus, under the assumptions of scenario 1, the probability of failure to obtain the planned profit for the company will be $50,8 \%$.

Checking how the probability of not achieving any profits changes depending on the size of the sample:

- for 10 randomly selected numbers

$\mathrm{P}($ Profit <52 164)

$>$ pnorm(52 164, mean(Profit), sd(Profit))

[1] 0,4886539

- for 100 randomly selected numbers

$\mathrm{P}$ (Profit <52 164)

$>$ pnorm(52 164, mean(Profit), sd(Profit))

[1] 0,5459279

- for 1000 randomly selected numbers

$\mathrm{P}$ (Profit <52 164)

$>$ pnorm(52164, mean(Profit), sd(Profit))

[1] 0,4933654 
Table 5. Second Scenario Assumptions (source: self study)

\begin{tabular}{|c|l|r|c|}
\hline No. & \multicolumn{1}{|c|}{ Item } & \multicolumn{1}{c|}{ Plan } & Possible realization \\
\hline A & Net revenues from sales & 100000 & {$[80000 ; 120000]$} \\
\hline B & Operating expenses & 60000 & {$[48000 ; 72000]$} \\
\hline D & Other operating revenues & 1000 & {$[800 ; 1200]$} \\
\hline E & Other operating expenses & 600 & {$[480 ; 720]$} \\
\hline G & Financial revenues & 30000 & {$[24000 ; 36000]$} \\
\hline H & Financial expenses & 6000 & {$[4800 ; 7200]$} \\
\hline N & Net profit (loss) & 52164 & \\
\hline
\end{tabular}

- for 10000 randomly selected numbers

$\mathrm{P}$ (Profit $<52$ 164)

$>$ pnorm(52 164, mean(Profit), sd(Profit))

[1] 0,4950574

- for 100000 randomly selected numbers

$\mathrm{P}($ Profit $<52$ 164)

$>$ pnorm(52 164, mean(Profit), sd(Profit))

[1] 0,4988596

- for 1000000 randomly selected numbers

$\mathrm{P}($ Profit $<52$ 164)

$>$ pnorm(52 164, mean(Profit), sd(Profit))

[1] 0,5004996 .

It can be seen from the above calculations that regardless of the multiplicity of tests, the probability of not achieving target profit is about $50 \%$. Common sense should therefore be adopted in the selection of the sample size to allow acceptable times for calculations.

\subsubsection{Scenario 2}

Scenario assumptions:

- variation specified in the profit and loss statement differs from the plan values by $\pm 20 \%$,

- all listed components are random variables uniform distributed with parameters $a$ and $b$, where:

- $a$ is the beginning of the interval,

- $\quad b$ is end of range established in Table 5 .

We have:

- net revenues from sales are random variable $\mathrm{p} 1$

with parameters $a=80000, b=120000$

(p1 U $(80000,120000))$

- operating expenses are random variable $\mathrm{k} 1$ with parameters $a=48000, b=72000$

$(\mathrm{k} 1 \sim \mathrm{U}(48000,72$ 000))
- other operating revenues are random variable $\mathrm{p} 2$ with parameters $a=800, b=1200$ (p2 $\mathrm{U}(800,1200))$

- other operating expenses are random variable $\mathrm{k} 2$ with parameters $a=480, b=720$

$(\mathrm{k} 2 \sim \mathrm{U}(480,720))$

- financial revenues are random variable $\mathrm{p} 3$ with parameters $a=24000, b=36000$ (p3 U(24 000, 36 000))

- financial expenses are random variable $\mathrm{k} 3$ with parameters $a=4800, b=7200$ (k3 U(4 800, 7 200))

A value is drawn for each of the above, assuming uniform distribution, and the result is stored as a variable. The pattern is replicated for the rest of the calculations, leading to a net profit shown in Fig. 2.

Basic measures of location and dispersion for Profit:

- highest profit that the firm may achieve in accordance with the assumptions of scenario 2 :

$>\max ($ Profit)

[1] 75 164,03

- minimum profit:

$>\min$ (Profit)

[1] 27387,52

- average profit with randomly selected parameters:

$>$ mean(Profit)

[1] 54405,42

- 2standard variation:

$>\operatorname{sd}($ Profit) 2

[1] 10483,12 


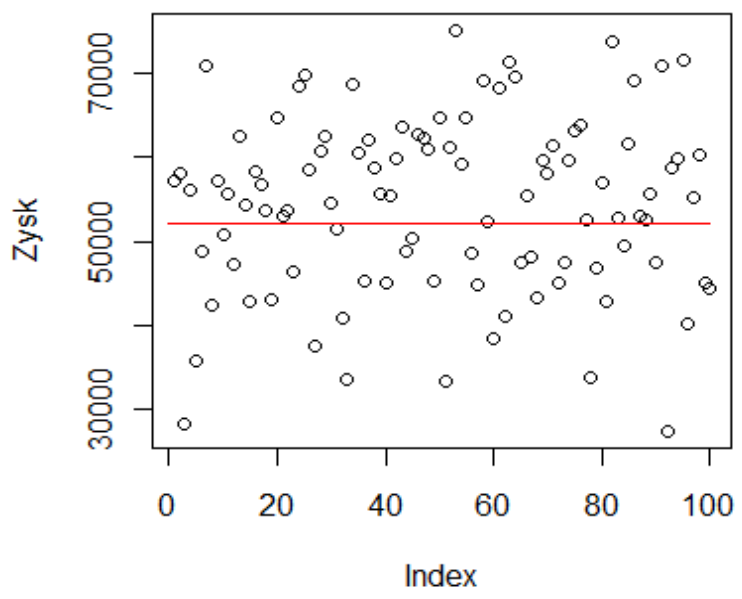

Figure 2. Profit values obtained in scenario 2 (source: self study)

Verification if the Profit function is normally distributed at significance level $\alpha=0,05$.

- lillie.test(Profit)

Lilliefors (Kolmogorov-Smirnov) normality test data: Profit

$\mathrm{D}=0,0621, \mathrm{p}$-value $=0,4498$

Coefficient $p$-value $=0,4498$, therefore it can be agreed that the sample is normally distributed.

The size of the probability that the financial result achieved will be less than planned:

- $\operatorname{pnorm}(52$ 164, mean(Profit), sd(Profit))

\section{[1] 0,4153468}

Thus, under the assumptions of scenario 2, the probability of failure to obtain the planned profit for the company will be $41,53 \%$.

\subsubsection{Scenario 3}

Scenario assumptions:

- variation specified in the profit and loss statement differs from the plan values by $\pm 20 \%$.

- all listed components are random variables triangular distributed with parameters a, b, c, where:

- $a$ is the beginning of the interval,

- $\quad b$ is end of the interval,

- $\quad c$ is middle of range established in Table 6.

We have:

- net revenues from sales are random variable $\mathrm{p} 1$ with parameters $\mathrm{a}=80000, \mathrm{~b}=120000, \mathrm{c}=$ 100000 (p1 Tr(80 000, 120000,100000$))$

- operating expenses are random variable $\mathrm{k} 1$ with parameters $\mathrm{a}=48000, \mathrm{~b}=72000, \mathrm{c}=60000$ (k1 Tr(48 000, 72 000, 60 000))

- other operating revenues are random variable $\mathrm{p} 2$ with parameters $\mathrm{a}=800, \mathrm{~b}=1200, \mathrm{c}=1000$ (p2 $\operatorname{Tr}(800,1200,1000))$

Table 6. Third Scenario assumptions (source: self study)

\begin{tabular}{|c|l|c|c|}
\hline No. & \multicolumn{1}{|c|}{ Item } & \multicolumn{1}{c|}{ Plan } & Possible realization \\
\hline A & Net revenues from sales & 100000 & {$[80000 ; 120000]$} \\
\hline B & Operating expenses & 60000 & {$[48000 ; 72000]$} \\
\hline D & Other operating revenues & 1000 & {$[800 ; 1200]$} \\
\hline E & Other operating expenses & 600 & {$[480 ; 720]$} \\
\hline G & Financial revenues & 30000 & {$[24000 ; 36000]$} \\
\hline H & Financial expenses & 6000 & {$[4800 ; 7200]$} \\
\hline N & Net profit (loss) & 52164 & \\
\hline
\end{tabular}




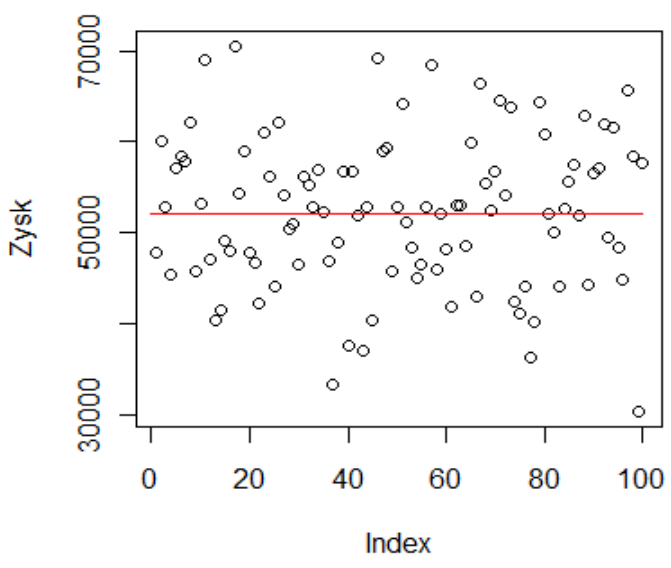

Figure 3. Profit values obtained in scenario 3

(source: self study)

- other operating expenses are random variable $\mathrm{k} 2$ with parameters $a=480, b=720, c=600$

$(\mathrm{k} 2 \sim \operatorname{Tr}(480,720,600))$

- financial revenues are random variable $\mathrm{p} 3$ with parameters $a=24000, b=36000, c=30000$ (p3 $\operatorname{Tr}(24000,36000,30000))$

- financial expenses are random variable $\mathrm{k} 3$ with parameters $a=4800, b=7200, c=6000$ (k3 Tr(4 800, 7 200, 6 000))

A value is drawn for each of the above, assuming uniform distribution, and the result is stored as a variable. The pattern is replicated for the rest of the calculations, leading to a net profit shown in Fig. 3.

Basic measures of location and dispersion for Profit:

- highest profit that the firm may achieve in accordance with the assumptions of scenario 3.:

$>\max$ (Profit)

[1] 70499,44

- minimum profit:

$>\min ($ Profit)

[1] 30355,54

- average profit with randomly selected parameters: $>$ mean(Profit)

[1] 52304,2

- standard variation:

$>$ sd(Profit)

[1] 8313,398

Verification if the Profit function is normally distributed at significance level $\alpha=0,05$.

- lillie.test(Profit)

Lilliefors (Kolmogorov-Smirnov) normality testdata: Profit

$\mathrm{D}=0,0481, \mathrm{p}$-value $=0,8247$
Coefficient p-value $=0,8247$, therefore it can be agreed that the sample is normally distributed.

For the Kołmogorov-Smirnov's test:

- s.test(Profit,ptriangle,min(Profit),max(Profit),mean( Profit))

One-sample Kolmogorov-Smirnov test data: Profit

$\mathrm{D}=0,0942, \mathrm{p}$-value $=0,3372$

alternative hypothesis: two-sided

Coefficient $p$-value $=0,3372$, therefore it can be agreed that

Profit $\sim \operatorname{Tr}(\min$ (Profit), max(Profit), mean(Profit)).

The size of the probability that the financial result achieved will be less than planned:

- ptriangle

(52164,min(Profit),max(Profit),mean(Profit))

[1] 0,539787

Thus, under the assumptions of scenario 3 , the probability of failure to obtain the planned profit for the company will be about $54 \%$.

\section{$7 \quad$ Summary}

Various aspects should be taken into consideration in risk assessment. This is the reason why this task within risk management involves various scientific disciplines: mathematics, psychology, law etc. The impact on risk assessment by the decision maker is not only a quantitative aspect but also a qualitative aspect.

The application of mathematical and statistical methods for risk assessment presents many benefits but also many challenges. On the one hand, we can use the generation of random variables with a specific, 
desired schedule to achieve our objectives; on the other hand, to start working and be able to interpret the results, we are forced to make several assumptions.

In this case, the starting point is a standard Profit and Loss Account, created by each company as an annual statement. It has become the basis for discussion on the impact of various factors on its individual components.

Since it is impossible to accurately plan the future of the individual components of the company's financial results, we can treat these values as random. If, additionally, we are given in advance acceptable deviations from the planned size of profit (loss) and impose on them a particular distribution of random variables, then it is possible, by using the R-project program, to choose random values for all elements of the Profit and Loss Account. The calculation of profit (loss) in accordance with the Profit and Loss Accounting method allows the observation of changes in the business plan resulting from unforeseen random events that affect the individual elements of the financial result. Furthermore, under these conditions it has become possible to calculate the probability that the company will not reach the planned profit in the current year.

\section{$8 \quad$ References}

[1] Bácskai T. et al. - Chozjaistwennji risk i metody jewo izmerenia. Ekonomika, Moscow 1979.

[2] BaFin - Aufsichtsrechtliche Mindestanforderungen an das Risikomanagement (MaRisk VA) [in] Rundschreiben (VA) der Bundesanstalt für Finanzdienstleistungsaufsicht, 3/2009.

[3] Basel Committee on Banking Supervision - Trends in Risk Integration and Aggregation, 2003.

[4] Bernstein P.L. - Przeciw bogom. Niezwykte dzieje ryzyka, WIG-PRESS, Warszawa 1997.

[5] David S.R. - Safety Risk Aggregation: The Bigger Picture, 2010, http://www.sars.org.uk/old-sitearchive/forms/david.pdf
[6] Jonen A., Lingnau, V., Sagawe Ch. - Aufbau eines kognitionsorientierten Risikocontrollinginstrumentes. Unterstützung der Risikobewertung mittels des Analytic Hierarchy Process [in] Beiträge zur Controlling-Forschung, No. 12, Kaiserslautern 2007.

[7] Kerzner H. - Project Management: A Systems Approach to Planning, Scheduling, and Controlling. Tenth Edition, John Wiley and Sons, New York 2009.

[8] Lo A.W. - The Three P's of Total Risk Management [in] Financial Analysts Journal, January/February, Vol. 55, No. 1, pp. 13-26, 1999, doi: 10.2469/faj.v55.n1.2238.

[9] Pézier J. - Application-Based Financial Risk Aggregation Methods [at] 1st International Derivatives and Financial Market Conference, Campos de Jordao, Brazil, 2003.

[10] Rogowski W., Michalczewski A. - Zarzqdzanie ryzykiem $w$ przedsięwzięciach inwestycyjnych. $\mathrm{OE}$, Kraków 2005.

[11] Studenski R. - Ryzyko i ryzykowanie. Wydawnictwo Uniwersytetu Śląskiego, Katowice 2004.

[12] Tyszka T., Zaleśkiewicz T. - Racjonalność decyzji. Pewność i ryzyko. Polskie Wydawnictwo Ekonomiczne, Warszawa 2001.

[13] Tyszka T. (ed.) - Psychologia ekonomiczna. Gdańskie Wydawnictwo Psychologiczne, Gdańsk 2004.

[14] Wiśniewski E. - Podejmowanie decyzji. Wybrane zagadnienia. Wydawnictwo Uczelniane Politechniki Koszalińskiej, Koszalin 1998.

[15] Zaleśkiewicz T. - Percepcja dziatań ekonomicznych [in] Psychologia ekonomiczna (ed. T. Tyszka), Gdańsk 2004.

[16] Zellmer G. - Risikomanagement, Die Wirtschaft, Berlin 1990.

[17] ISO/IEC Guide 73. 2003. Risk ManagementVocabulary, 2003.

[18] The Orange Book: Management of Risk - Principles and Concepts. ISBN 1-84532-044-1, HM Treasury 2004. 